\title{
WHAT ABOUT SCIENTIFIC COLLABORATION IN AGRICULTURE? A BIBLIOMETRIC STUDY OF PUBLICATIONS ABOUT WHEAT AND POTATO (1996-2016)
}

\author{
Lilian Cervo Cabrera (1), Edson Talamini (2), Homero Dewes (3)
}

Graduate Program in Agribusiness, Center for Studies and Research in Agribusiness, Federal University of Rio Grande do Sul. Federal University of Rio Grande do Sul, Brazil. Bento Gonçalves Avenue, 7712, 91540-000, Porto Alegre, RS, Brazil, e-mail: liliancabrera_86@yahoo.com.br (2) Department of Economics and International Relations, Center for Studies and Research in Agribusiness, Federal University of Rio Grande do Sul. E-mail: edson.talamini@ufrgs.br (3) Department of Biophysics, Biosciences Institute and Interdisciplinary Center for Studies and Research in Agribusiness,

Federal University of Rio Grande do Sul, e-mail: hdewes@ufrgs.br.

\begin{abstract}
In evolutionary biology, the ability to cooperate may have determined the success of the human race over other races. In agriculture, it seems to be the key to increasing agricultural productivity to feed nine billion people. Thinking about it, the main scope of this work is to measure the cooperation scientific collaboration - through the co-authorships analysis in the agriculture field of literature. The goal was to map the countries that collaborate scientifically in the food security area. We considered articles published in the last 20 years in
\end{abstract}

\section{Introduction}

In a series of recent studies comparing human beings with lower primates, scientists do not hesitate to link the success of human evolution to the ability to collaborate (Nowak, 2006; Despain, 2010; Nowak, 2012). According to social anthropologist Kim Hill, humans are not special because of the size of their brain. That's not why space rockets are built, anyone could do it alone, she says. There are rockets because 10,000 people cooperate to produce information (Wade, 2011).

In Hill's view, the two main traits that sustain human evolutionary success are the unusual capacity for cooperation between people without family ties and the social learning, i.e., the ability to copy and learn from what others are doing. With these two skills, a large social network can generate knowledge and innovations much more easily than a cluster of small isolated groups (Wade, 2011).

If cooperation and social learning were able to determine the success of one race over others over thousands of years, wouldn't these two skills, even today, be the lever for the globalization of some areas of knowledge? Wouldn't they be key elements for advancing sequencing and knowledge of the human and
Web of Science and the results were analyzed using the VOSviewer software. The results indicate that the gene (the term "gene") was the predominant theme in the density of the terms in the articles and also in the studied subjects. The United States is the country that most contributes, followed by China. These two countries also have the largest mutual collaboration, with 254 connections between them.

Keywords: cooperation, co-author, co-occurrence, indicators, agribusiness, bibliometrics.

other genetic map (genome), or for ensuring global food security? In agriculture, according to a report by twelve G20 countries, some progress is being made, but much more can and should be done in support of a more productive and sustainable system of food production. According to the report, collaboration is the key to increasing agricultural productivity to feed nine billion people (Organization for Economic Cooperation and Development, 2012).

In any case, even if the answers to these questions are positive, how can we measure cooperation? What metrics could be used to measure cooperation between people and also if it has been generating social learning and scientific advancement, especially for agriculture around the world?

Thinking about this, the main scope of this work is to measure cooperation - scientific collaboration - through the analysis of coauthored (a technique widely used in bibliometrics studies) in the agricultural literature. Thus, the objective of this article is to map authors, institutions and countries that collaborate more scientifically in food security. For this, articles published in the last 20 years (1996 to 2016) of the Web of Science database were considered and the results analyzed through VOSviewer software. 


\section{Scientific collaboration and bibliometrics studies}

Collaboration is a social process and human interaction that can happen in different ways and for different reasons (Vanz, 2009). In nature, among animals, there are many examples of collaboration between species, such as smaller fish that eat larger fish parasites and nitrogen-fixing bacteria that bind to the roots of plants (Pennisi, 2009). Over the decades, biologists have been discussing cooperation, striving to understand it in the face of evolutionary theories.

In the main dictionaries, the word collaboration means "to cooperate, to help". The concept is broad and, in the case of scientific collaboration, there is still no consensus on how to measure help between scientists. In classical understanding, two people collaborate when they share data, equipment and/or ideas in a project, which usually results in publications (Katz and Martin, 1997). However, a person can also be considered a contributor by providing materials and assisting in trials (Vanz, 2009). Latour and Woolgar (1997), for example, in reporting on Bruno Latour's experience in a laboratory in the US, acknowledge that each stage of the work generates a number of articles and some processes will only be described and published in the literature with the help of external collaborators to the lab.

In the literature, scientific collaboration often appears related to co-authorship. Katz and Martin (1997) evaluate that co-authorship is not synonymous of collaboration, because authors are not always responsible for the work. In addition, not all collaboration between scientists results in publications. Luukkonen, Persson and Sivertsen (1992) point out that collaboration between authors can also appear in the acknowledgments. Despite this, co-authorship has been widely used by bibliometry to study collaboration between people, institutions and countries. The same authors cite as advantages of co-authoring, the possibility of checking the data by other authors and the ease and practicality with which the method allows the analysis of large samples, allowing more significant results than case samples (Katz and Martin, 1997). Bibliometry can be described as an area of knowledge that focuses on quantitative measurement of science production. Smith's paper (1958) is considered the first in which articles in co-authorship could be used as a measure of collaboration between researchers. From it, Solla Price (1976) also defended the idea of using co-authorship to estimate collaboration among researchers. From there, it awoke the investigation of researchers interested in the study of network dynamics, considered complex social networks, and of Network Theory (Barabási et al., 2002; Balancieri et al., 2005). Much has been discussed about the measurement, characterization and evaluation of science, that is, about the evaluation of the research results of scientists and scholars, who have their product presented in different ways.

In agriculture, bibliometric studies have been used in recent years to measure publications in agricultural science, one of the most traditional in the world. Among the most extensive investigations, we highlight that of Sagar et al. (2013). Based on bibliographic records of publications indexed in Web of Science, they analyzed all agricultural science research publications in the world, from 1993 to 2012. In addition, the biliometric studies are present in publications that investigate from the use of land and water in different countries (Hamidov et al., 2014, Yan et al., 2016) to collaboration between different countries (Zhou et al., 2013). Similarly, emerging issues in agriculture such as urban agriculture (Zhu and Liu, 2017), organic agriculture (Alexandrei et al., 2015) and the use of nanotechnology (Stopar, 2016; Manjunatha et al., 2016) also have been objects of bibliometric studies in recent years.

In biliometric studies, different tools can be used to construct and visualize bibliometric maps, such as Pajek, VOSviewer, Mapequation, Netdraw, UCINET and others. With VOSviewer, maps can be created from network data, using mapping and grouping techniques. The software allows clusters to be created by clustering and can be used to construct maps of authors or journals (based on data cocitation) or for the construction of keyword maps (based on co-occurrence data). VOSviewer develops a clustering process through the implementation of the VOS mapping algorithm, which minimizes the distance between similar elements. The strength of association of co-occurrences is measured by the number of times the word appears. For each cooccurrence, the most relevant terms are selected based on the number of times they were cited (Van Eck and Waltman, 2010). Already the co-citation force is determined by direct citation relations (Waltman and Van Eck, 2012; 2013). In both cases, the size of a cluster reflects the number of publications belonging to the cluster or the frequency that words occur. The distance between two clusters approximately indicates the relatedness of the clusters in terms of citations/occurrence. Clusters that are located close to each other tend to be strongly related, while clusters that are located further away from each other tend to be less strongly related (Van Eck and Waltman, 2017).

\section{Methodology}

This study is an exploratory research and the source used was the Web of Science (WoS), a multidisciplinary database of Thomson Reuters, used worldwide for the analysis of scientific production. There was a restriction on the type and period of publications, so only articles published from 1996 to 2016 were searched. In the data collection, the option of advanced search was used, which allows the use of Boolean logic. The re- 
search was carried out with the Proxy of Federal University of Rio Grande do Sul (UFRGS) and the keywords were chosen with the purpose of analyzing the characteristics of the publications of the area of agriculture related to the theme of food security. As an integrant part of a doctoral research - which investigates the role of scientific collaboration as a disease mitigation strategy for wheat and potatoes, in particular - the research was limited especially for these two crops. Thus, the field TS (Topic) was used, referring to the topic of the research and the following search expression was constructed: TS $=($ agri $*$ AND food security AND wheat OR potato). Considering the large number of publications found, it was decided to refine the research by categories of the Web of Science that would encompass food safety issues. Thus, only articles belonging to the 15 major categories below were selected: (Plant Sciences OR Agronomy OR Food Science Technology OR Biochemistry Molecular Biology OR Agriculture Multidisciplinary OR Biotechnology Applied Microbiology OR Chemistry Applied OR Entomology OR Horticulture OR Nutrition Dietetics OR Genetics Heredity OR Environmental Sciences OR Microbiology OR Engineering Chemical OR Multidisciplinary Sciences).

Data collection was performed on July 2, 2016 and 18,998 articles were found. The data was imported from the Web of Science into txt format files. The VOSviewer software, developed by the Center for Science and Technology Studies of the University of Leiden, The Netherlands, was used to organize and analyze the data. The tool allows the organization and the accomplishment of descriptive analyzes of bibliographic records extracted from databases such as WoS.

In the end, the objective of this article is to measure the scientific collaboration in the area of food security. From its measurement it is possible to identify international collaboration networks, as well as to map the evolution of the different fields of science and technology to food security.

All figures in the present research are also available digitally in an online repository (https://doi.org/10.6084/m9.figshare.5229709.v1).

\section{Results and Discussions}

The results showed 18,998 articles relating the terms "agri", "food security" and "wheat" or "potato" in journals of the selected categories. The first analysis was the co-occurrence of words, with the objective of identifying contents that could directly or indirectly indicate the relationship of these terms with the different scientific fields that can be encompassed by food security. Figure 1 shows a map of the words that most occur in the titles and abstracts of the articles.

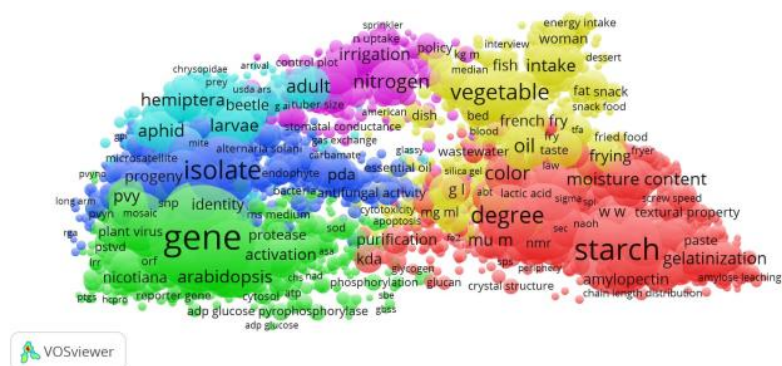

Figure 1. Map of the words that occur in the titles and abstracts of the analyzed articles

It is possible to note that in the map, there is the presentation of the words in groups or clusters (defined by color) and different sizes.

In the map above, it is observed that six clusters are identified and those that appear next share high similarity, whereas further clusters denote low similarity. Each constituent circle of the network is one of 4720 words that had 12 or more occurrences. VOSviewer software selected these 4720 words, or $60 \%$ of the most relevant terms in the titles and abstracts of articles reviewed and identified 688,039 links between these words. The words "gene" and "starch" are the ones that appear in larger size, and occurred 2703 and 1930 times, respectively, in the articles analyzed. In the cluster of green color, in which the word "gene" appears, they appear related to it, words like "protease", "plant virus", "mosaic", "activation". In the cluster of red color, linked to the word "starch", also appear words like "moisture content", "amylopectin", "textural property". In addition, other words appear in three other clusters of different colors, like: "vegetable", "intake", "food", "taste" (in the yellow cluster); "Nitrogen", "irrigation", "uptake" (in the pink cluster); "Larvae", "adult" (in the light blue cluster) and "isolate", "progeny" and "molecular marker" (in the dark blue cluster).

Thus, it is understood that in the green cluster as in dark blue, the focus of the publications is on genetics, the light blue color is on insects and pests. In the pink cluster the focus is on the agricultural management, the yellow one is on diets and food patterns, while in the red cluster is on chemical and organoleptic characteristics of food. In addition, the VOSviewer software pointed out that, of the 4,720 words, $24 \%$ of them (1130 words) occurred in the red cluster articles, that is, they had terms referring to the chemical and organoleptic characteristics of the foods. The green and dark blue clusters, that deal with genetics, performed together $40 \%$ of the words found (965 to 959 words, respectively), as the light blue cluster, which deals with insects and pests, showed $9 \%$ of the words found, while the pink and yellow clusters, which deal with agricultural management and diets and food patterns, presented $13 \%$ and $14 \%$ each. 
In Figure 2 we can observe the density of the terms. The red color indicates higher density, which means that these words have greater weight or importance; followed by orange, yellow, green and blue colors. Therefore, genetics (the term "gene") stands out as the main focus of discussions during the analyzed period.

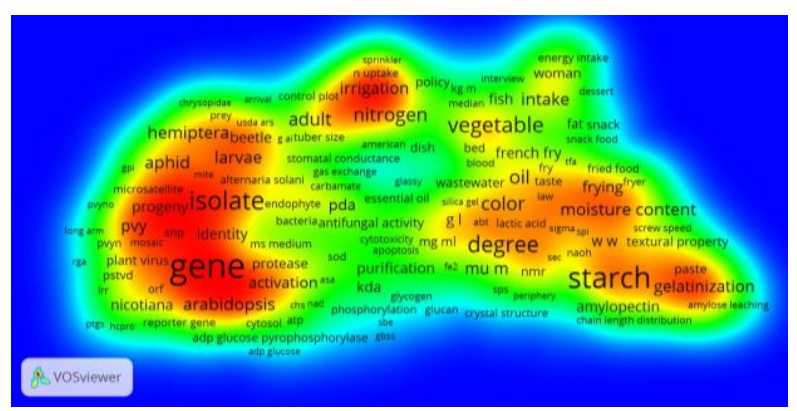

Figure 2. Density map of the words that occur in the titles and abstracts of the analyzed articles. The red color indicates higher density, which means that these words have greater weight or importance; followed by orange, yellow, green and blue colors.

As this visualization is indicated for a quick identification of the most important areas of the map, Figures 3 and 4 allow identifying the terms that were searched together with the most used words and that were presented in Figure 2. In other words, they explain the stronger relationships of the main themes, namely, those who were most often studied together. In Figure 3 , the composition of a cohesive group of words around the term "gene" is shown.

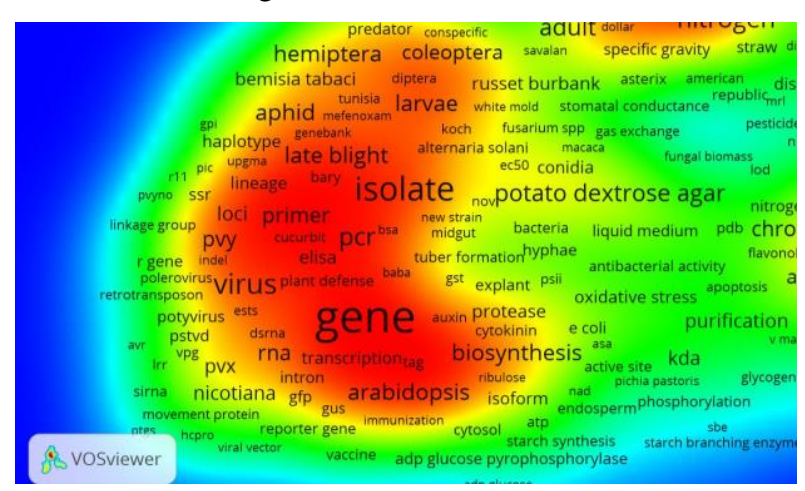

Figure 3. Density map highlighting the word "gene" that occurs in the titles and abstracts of the articles analyzed. The red color indicates higher density, which means that these words have greater weight or importance; followed by orange, yellow, green and blue colors.

The words "isolate", "virus", "late blight", "primer" and "PCR" appear in particular. They refer to the technique used in molecular biology and plant breeding (PCR) and plant diseases (late blight and $\mathrm{Y}$ virus). In potato and tomato, for example, late blight and $\mathrm{Y}$ virus can compromise all production. Genetic improvement (and the development of resistant cultivars) has been pointed out as the best way to control them, justifying the interest in the subject and, consequently, the great occurrence of these terms in the publications.
Figure 4 shows the composition of a smaller, but also cohesive, group of words around terms such as "irrigation", "nitrogen" and "field experiment", which refer to the management of agricultural crops.

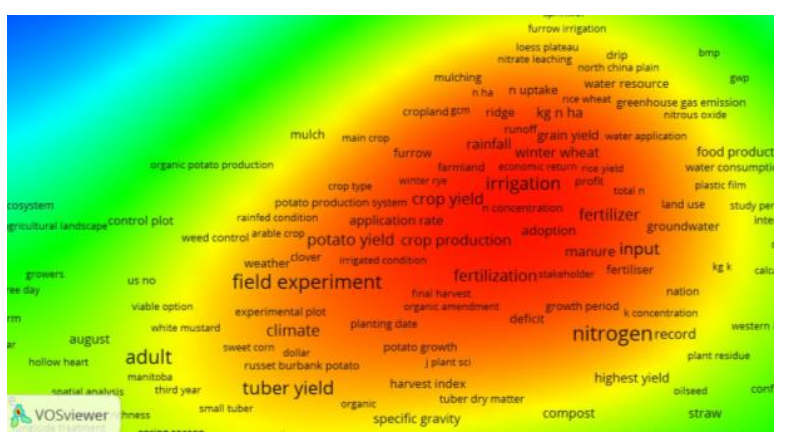

Figure 4. Density map highlighting the word "irrigation" that occurs in the titles and abstracts of the analyzed articles.

The red color indicates higher density, which means that

these words have greater weight or importance; followed by orange, yellow, green and blue colors.

Linked to them are the words "fertilization", "winter wheat", "potato yield", "input" and "climate". All of these are terms indicating that the production factors and the wheat and potato management practices are highlighted themes in the published articles. It is observed that this group portrays the discussions related to food production, related to agriculture, yield and crop efficiency and the resources needed for its production, such as water and fertilizers. In addition to the necessary conditions for food production, it also highlights irrigation, and climate-related implications, issues from the perspective of food security. After the construction of the terms maps of the scientific production of the area, the results of the scientific collaboration of the authors, countries and institutions of the area are presented below. At a micro level, the authors are the producing individuals and agents of science; and at a higher level, research agents are the institutions to which they are a part, and consequently the countries to which those institutions belong. From a total of 49,198 authors, the map in Figure 5 shows 2937 of them, that is, those who have at least five published articles.

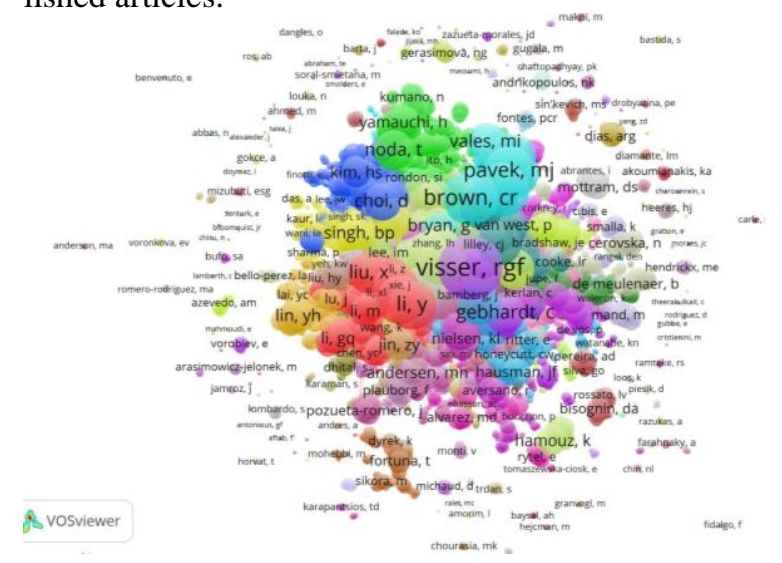


Figure 5. Map of the collaboration of the main authors of the analyzed articles.

According to the software, the authors are divided into 220 different clusters and there are 17,816 connections between them. The largest cluster has 436 authors and is identified on the map by red color. The central author of this cluster (Li, Y.) has 61 publications and 210 collaborations. With the largest number of collaborations in the red cluster, his work investigates the impacts of agricultural practices on the environment and also fertilization and irrigation in cropping systems such as wheat, corn and rice. Throughout the map, the most productive author (Visser, RGF) has 106 articles and 493 collaborations in his works. He is the author with the largest number of publications and also with the greatest collaboration of all the clusters. His works are focused on biotechnology, genetics, molecular biology and plant breeding and he is the central author of the purple color cluster. In the light blue cluster, there is also another author (Brown, CR) who stands out with 56 publications and 355 collaborations. He is the lead author of this cluster and research on plant breeding, especially potato, and resistance of these plants to fungi, nematodes and viruses. In the other clusters, there is no one author who stands out from the others, nevertheless, the map shows a strong link between authors within each cluster. If an overall average is made (of the 220 identified clusters and the connections between the authors), it can be said that each map cluster has about 80 collaborations, so each author would have, on average, six collaborations. As the number of collaborations is not the same in all clusters or for each author, in Figure 6 is possible to observe the density of the clusters and to identify those with the greatest number of collaborations.

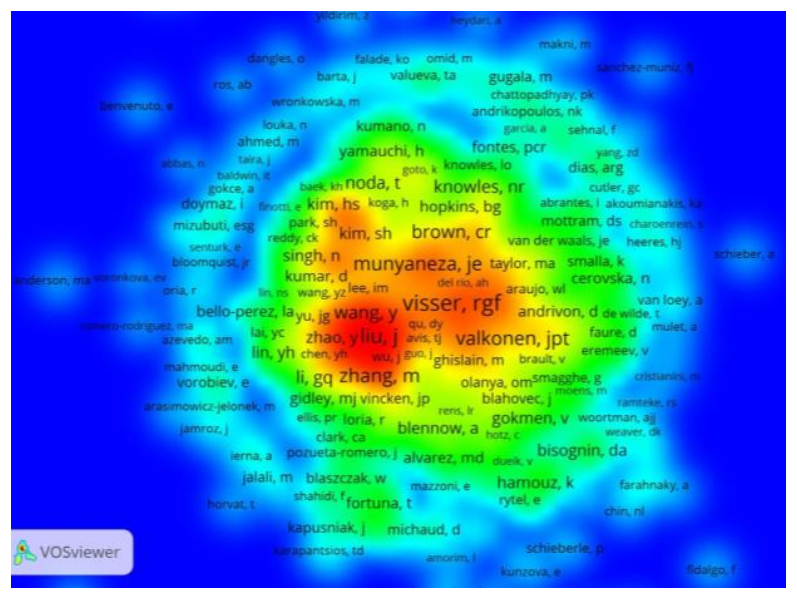

Figure 6. Map of the collaboration density of the main authors of the analyzed articles. The red color indicates higher density, which means that these words have greater weight or importance; followed by orange, yellow, green and blue colors.

The density of the network is represented by the color variation, from red to green, with a greater or lesser collaboration among the authors. The reddish-colored manuscripts are those with the highest number of connections. Note that the authors already cited are, in fact, the ones that have the most collaboration in the researched area. Thus, in addition to knowing the authors who collaborate and collaborate more, and also their research themes, it is important to know to which institutions the authors belong and also from which countries they are. To do this, Figure 7 presents a map with collaboration by institutions.

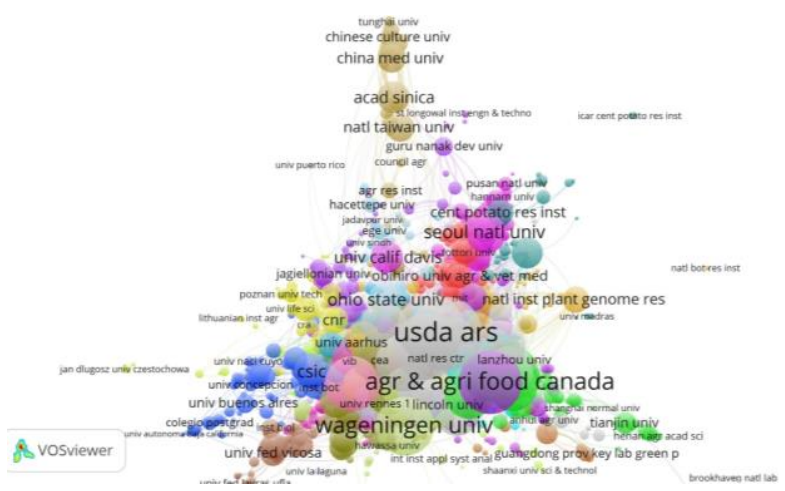

Figure 7. Map of the collaboration of the main institutions of the analyzed articles.

For the construction of this map, the software identified 9511 institutions throughout all analyzed articles, 1402 of these form the map (those with at least five documents) that is divided into 55 clusters. It is observed that the institution with more collaboration is the Agriculture Research Service (ARS) of the United States Department of Agriculture (USDA). It is responsible for 494 articles published in collaboration with 651 institutions and is located in the gray cluster. Along with it, other institutions such as Cornell University, Washington State University and Wisconsin University also form this cluster, the most collaborative of the entire map. Agriculture and Agri-Food Canada (AAFC) is another collaborative institution that stands out on the map in the purple cluster. She has 400 articles published in co-authoring with 486 other institutions. Along with these, a third cluster attracts attention, the dark yellow one, in which Wageningen University is. It appears in 248 publications and counts with the collaboration of 419 institutions in the publication of these articles. The green cluster, although not very prominent on the map, also draws attention to the homogeneity of the circles - located below Agriculture and Agri-Food Canada (AAFC) - which indicates the similar collaboration of the Chinese institutions in the cluster, Chinese Academy of Sciences and China Agricultural University. From Figure 8, it is possible to detail the density of the collaborations of these leading institutions. 


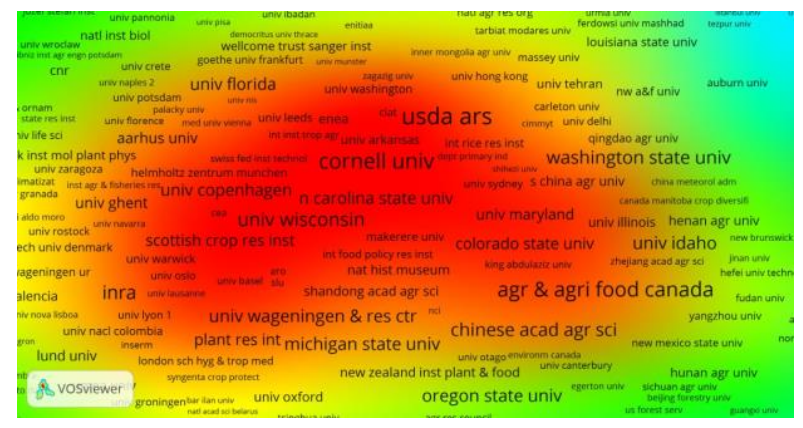

Figure 8. Map of the density of the collaboration of the main institutions of the analyzed articles. The red color indicates higher density, which means that these words have greater weight or importance; followed by orange, yellow, green and blue colors.

They are located in the red part of the map, that is, the region that has the largest number of connections. In Figure 9 there is the presentation of the map with the countries that most collaborate scientifically.

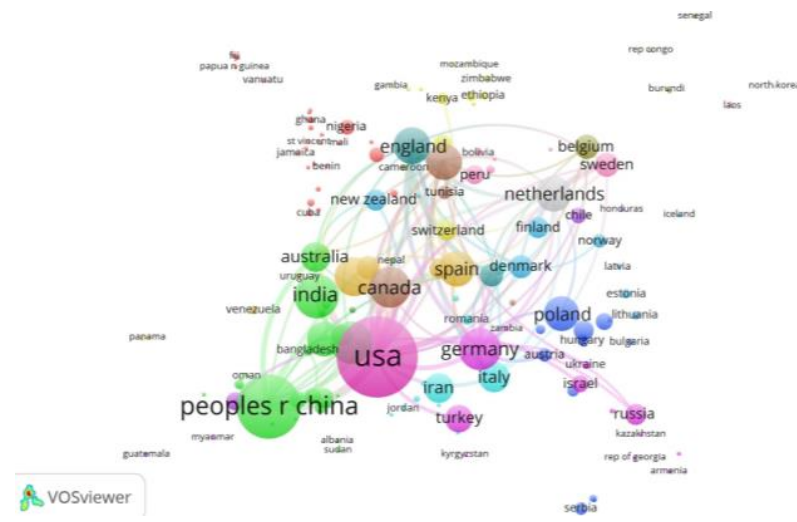

Figure 9. Map of the collaboration of the main countries of the analyzed articles.

Like the previous ones, the map above was constructed from the co-authoring analysis, in which each country should have at least one document. The software identified 21 different clusters and 1689 connections between each country. The United States and China are the countries that have the biggest collaboration, although they are in different clusters. From the analyzed articles, $19 \%$ of them, that is, 3718 articles have American origin and are responsible for 1934 coauthored papers, being the United States the country that collaborates more in the map. China comes next, responsible for 2327 articles (12\% of the total) and 968 collaborations. These two countries also have the largest mutual collaboration, with 254 connections. Also noteworthy is the collaboration of England and France which, although they are further away from the United States and China and in different clusters, have great importance in international scientific collaboration. Figure 10 shows the density map of these collaborations.

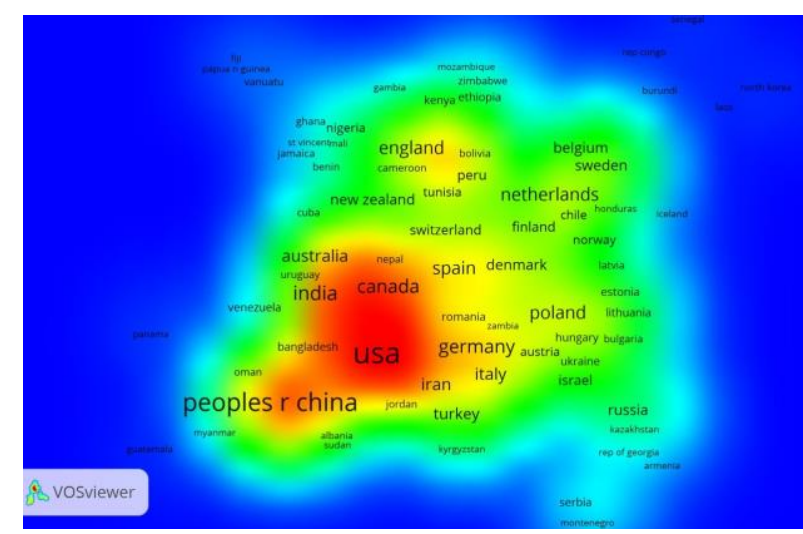

Figure 10. Map of the density of the collaboration of the main countries of the analyzed articles. The red color indicates higher density, which means that these words have greater weight or importance; followed by orange, yellow, green and blue colors.

Also noteworthy are the contributions made by Canada, India, Germany and Australia to the United States and China.

In Table 1, there is a presentation of the collaborations of the main countries.

\begin{tabular}{l|r|r}
\hline Country & Number of papers & Number of collaboration \\
\hline United States & 3718 & 1934 \\
\hline China & 2327 & 968 \\
\hline England & 764 & 960 \\
\hline Germany & 785 & 894 \\
\hline France & 734 & 829 \\
\hline Netherlands & 711 & 745 \\
\hline Canada & 967 & 533 \\
\hline Spain & 728 & 528 \\
\hline Italy & 525 & 498 \\
\hline Scotland & 315 & 442 \\
\hline Sweden & 335 & 434 \\
\hline Australia & 504 & 433 \\
\hline Japan & 1002 & 431 \\
\hline Denmark & 304 & 372 \\
\hline Belgium & 331 & 331 \\
\hline Peru & 218 & 305 \\
\hline India & 686 & 297 \\
\hline South Korea & 236 & 287 \\
\hline Switzerland & & 278 \\
\hline Brazil & & \\
\hline & & \\
\hline
\end{tabular}

Table 1. Relationship between the main countries and the number of articles and collaborations of each one 
It can be observed in the table that countries with the highest number of publications are not always the ones with the greatest collaborations. Japan, India and Brazil, for example, stand out for the large number of publications each, but are less collaborative than other countries like Canada, Spain and Australia. Thus, although China and the United States are the most scientifically productive countries and also the biggest collaborators, it can be said that this relationship is not always valid for other countries. In addition, it is important to note that, on the map, clusters with more countries do not always indicate those that collaborate more closely. Table 2 lists the clusters identified by the software and the number of countries found in each one of these clusters.

\begin{tabular}{|c|c|}
\hline Cluster & Number of countries \\
\hline 1 (red color) & 28 \\
\hline 2 (green color) & 23 \\
\hline 3 (dark blue color) & 14 \\
\hline 4 (yellow color) & 14 \\
\hline 5 (purple color) & 12 \\
\hline 6 (light blue color) & 11 \\
\hline 7 (blue color) & 9 \\
\hline 8 (dark yellow color) & 9 \\
\hline 9 (dark green color) & 8 \\
\hline 10 (light pink) & 8 \\
\hline 11 (color brown) & 6 \\
\hline 12 (color green-water) & 3 \\
\hline 13 (pink color) & 3 \\
\hline 14 (lilac) & 3 \\
\hline 15 & 2 \\
\hline 16 & 2 \\
\hline 17 & 2 \\
\hline 18 & 1 \\
\hline 19 & 1 \\
\hline 20 & 1 \\
\hline 21 & 1 \\
\hline
\end{tabular}

Table 2. Relationship between clusters and the number of countries in each cluster

According to the cluster map already presented in Figure 8, the United States and China are the countries that collaborate the most and are, respectively, in the green and pink clusters. The pink cluster is not the one that has more connected countries, on the contrary, it presents only three countries, nevertheless, the United States is the most collaborative of the entire map. The same thing happens with the red cluster on the map, with 28 countries. Despite the large number of countries in the same cluster, they do not collaborate with each other. This is because there is often collaboration between institutions in the same country and not necessarily with other countries, as it appears to be the case with the United States. Something similar is perceived with the European countries, like England and France, that have great collaboration alone or with neighboring countries. Viewed as a bloc, European Union countries lead total global publication output, producing a majority of the articles surveyed. In the case of China, despite belonging to a large cluster and researching similar topics, it prioritizes collaborating with the United States.

\section{Conclusions}

The objective of this work was to measure scientific collaboration in the area of food safety through the analysis of articles published in the Web of Science database. The first analysis of the 18,998 articles found, from 1996 to 2006, was that of word cooccurrence. It was carried out in order to identify the themes that appear in the publications and showed that the articles that contained the words "agri*", "food security", "wheat" and "potato" belong to five main scientific fields: 1) genetics, 2) insects and pests, 3) agricultural management, 4) diets and food standards, and 5) chemical characteristics of foods. In addition, genetics (the term "gene") was the subject that predominated in the analysis of the density of terms in the articles, standing out as the main focus of the discussions in the analyzed period. Genetic improvement (and the development of resistant cultivars) has been pointed out as the best way to control diseases in plants - including potatoes and wheat - and can justify the importance of the subject for food security and, consequently, the great occurrence of these terms in the publications.

In the co-authorship analysis, we tried to identify authors, institutions and countries that collaborate scientifically in works on food security. It was again identified that the authors who collaborate the most are those who research on biotechnology, genetics, plant reproduction and the development of resistant biotypes. In addition, they are also those authors that have more publications, reaffirming the importance of the theme in the works that involve food security.

In the maps of the institutions, it was verified that the institution that collaborates the most is the Agriculture Research Service (ARS) of the United States Department of Agriculture (USDA). It forms the most collaborative cluster and prioritizes its collaboration with other American universities such as Cornell University, Washington State University, and Wisconsin University. When the analysis moves to the level of countries, it 
can be seen that the United States and China are the countries that have the biggest collaboration, although they are in different clusters. In the articles analyzed, the United States is the most collaborative country, followed by China. These two countries also have the greatest mutual collaboration, with 254 connections between them. This may be a reflection of the growth of Chinese scientific research and also of the increase in the number of Chinese immigrants in the United States, mostly university students and skilled workers.

In general, the scientific production stored in the databases like Web of Science is an important source of information for the knowledge of a scientific field. As the most used database for evaluating indicators (such as co-occurrence of words and co-authorship), the use of Web of Science in this work was satisfactory. The use of VOSviewer software also met expectations, showing that it is possible to collect scientific indicators from public domain software. It is known that the results presented here do not represent the entire world scientific production on the subject researched, so even though the volume of articles analyzed has been high, they represent only a fraction of the total world scientific production. In addition, as an exploratory research, the terms searched were quite generic, which resulted in articles from different scientific fields related to food safety.

Among the possibilities for future studies, the in-depth study for specific scientific fields, such as genetics, is a research topic that can generate results relevant to the evaluation of science. In addition, the methodology could be applied to other databases, especially the patent bank and cultivars. Another possibility is the extension of the temporal sample to allow the evaluation of the development of scientific collaboration. The construction of indicators and metrics specific to each specific research area is also important for the evolution of the study. The methods used have already received some criticism regarding the representativeness of the use of words or coauthored to indicate the similarity between documents and the consequent characterization of a research area. Since words can be used with different meanings depending on the context, the study would require a knowledge of the boundaries of a given area prior to performing the analysis.

Despite the limitations, this work contributes to the understanding of scientific collaboration in the area of food safety. Thus, it is relevant for the analyzed period; however, the evaluations must be constant and periodic, since the databases are updated daily.

\section{References}

Aleixandre, J. L.; Aleixandre-Tudó; J. L.; Bolaños-Pizarro, M.; Aleixandre-Benavent, R. (2015). Mapping the scientific research in organic farming: a bibliometric review. // Scientometrics 105:1 (2015) 295-309.
Balancieri, R., Bovo, A. B., Kern, V. M., Pacheco, R. C. D. S., Barcia, R. M. (2005). An analysis of scientific collaboration networks under the new technologies of information and communication: a study in Lattes Platform. // Ciência da Informação 34:1 (2005) 64-77.

Barabási, A. L., Jeong, H., Néda, Z., Ravasz, E., Schubert, A., Vicsek, T. (2002). Evolution of the social network of scientific collaborations. // Physica A: Statistical mechanics and its applications 311:3 (2002) 590-614.

Despain, D. (2010). Early humans used brain power, innovation and teamwork to dominate the planet. Scientific American, 2010. https://www.scientificamerican.com/article/humans-brainpower-origins/ (2016-12-17).

Van E., N. J; Waltman, L. (2010). Software survey: VOSviewer, a computer program for bibliometric mapping. // Scientometrics $84: 2$ (2010) 523-538.

Van E., N. J; Waltman, L. (2017). Citation-based clustering of publications using CitNetExplorer and VOSviewer. // Scientometrics 111:2 (2017) 1053-1070.

Hamidov, A.; Katharina H,; Dagmar Balla (2014). Research on land use functions in Central Asia: A bibliometric analysis. // Proceedings of the Recca-Conference, Halle (Saale), Germany, 2014.

Katz, J. S.; Martin, B. R. (1997). What is research collaboration? // Research Police 26 (1997) 1-18.

Latour, B.; Woolgar, Steve (1997). A vida de laboratório: a produção dos fatos científicos. Rio de Janeiro: Relume Dumará, 1997. 310 p.

Luukkonen, T.; Persson, O.; Sivertsen, G. (1992). Understanding patterns of international scientific collaboration. // Science, Technology \& Human Values 17:1 (1992) 101-126.

Manjunatha, S. B.; Biradar, D. P.; Aladakatti, Y. R. (2016). Nanotechnology and its applications in agriculture: A review. // Journal of Farm Science 29:1 (2016) 1-13.

Nowak, M. A. (2006). Five Rules for the Evolution of Cooperation. // Science 314: 5805 (2006) 1560-1563.

Nowak, M. A (2012). Why We Help: The Evolution of Cooperation. // Scientific American, 2012. https://www.scientificamerican.com/article/why-we-helpevolution-cooperation/?responsive=false (2016-06-21).

Organization for Economic Cooperation and Development (OECD) (2012). Agriculture: G20 collaboration to improve agriculture productivity growth is key to feeding 9 billion people. https://www.oecd.org/g20/topics/agriculture-foodsecuri-

ty/agricultureg20collaborationtoimproveagricultureproductivityg rowthiskeytofeeding9billionpeople.htm> (2016-07-24).

Pennisi, E. (2009). On the origin of cooperation. // Science 325:5945 (2009) 1196-1199.

Sagar, A.; Kademani, B. S.; Bhanumurthy, K. (2013). Research trends in agricultural science: A global perspective. // Journal of Scientometric Research 201:2 (2013) 185-201.

Smith, M. (1958). The trend toward multiple authorship in Psychology. // American Psychologist Washington 13 (158) 596-599.

Solla P., Derek J. de (1976). O desenvolvimento da ciência: análise histórica, filosófica, sociológica e econômica. Livros Técnicos e Científicos, 1976.

Stopar, Karmen (2016). Presence of nanotechnology in agriculture: bibliometric approach. // Acta agriculturae Slovenica 107:2 (2016) 497-507. 
Vanz, Samile Andre de Souza (2009). The scientific collaboration networks in Brazil (2004-2006). // Doctoral dissertation. Federal University of Rio Grande do Sul, Porto Alegre, Brazil, 2009.

VOSviewer. Visualizing scientific landscapes. http://www.vosviewer.com/ (2016-07-14).

Zhou, Ping, Yongfeng Zhong, and Meigen Yu (2013). A bibliometric investigation on China-UK collaboration in food and agriculture. // Scientometrics 97:2 (2013) 267-285.

Zhu, ZheMin; ChunYan, Liu (2017). Bibliometric analysis in urban agriculture research. // Journal of Anhui Agricultural University 44:1 (2017) 177-184.

Wade, Nicholas (2011). Supremacy of a Social Network. The New York Times, 2011. http://www.nytimes.com/2011/03/15/science/15humans.html (2016-12-10)

Waltman, Ludo; Van Eck, Nees Jan (2012). A new methodology for constructing a publication-level classification system of science. // Journal of the American Society for Information Science and Technology 63:12 (2012) 2378-2392.

Waltman, Ludo; Van Eck, Nees Jan (2013). A smart local moving algorithm for large-scale modularity-based community detection. // European Physical Journal B 86:11 (2013) 471.

Yan, Peng; Chen, Yuan-Quan; Sui, Peng (2016). Status and trends of researches on agriculture water issues in North China Plain: Based on bibliometric methods. // Journal of China Agricultural University 9:23 (2016).

Copyright: (C) 2017. Cabrera (et al). This is an openaccess article distributed under the terms of the Creative Commons CC Attribution-ShareAlike (CC BYSA), which permits use, distribution, and reproduction in any medium, under the identical terms, and provided the original author and source are credited.

Received: 2017-01-20. Accepted: 2017-07-19

Cabrera, Lilian; Talamini, Edson; Dewes, Homero. What about scientific collaboration in agriculture? A bibliometric study of publications about wheat and potato (1996-2016) // Brazilian Journal of Information Studies: Research Trends. 11:3 (2017) p.17-25. ISSN 1981-1640. 